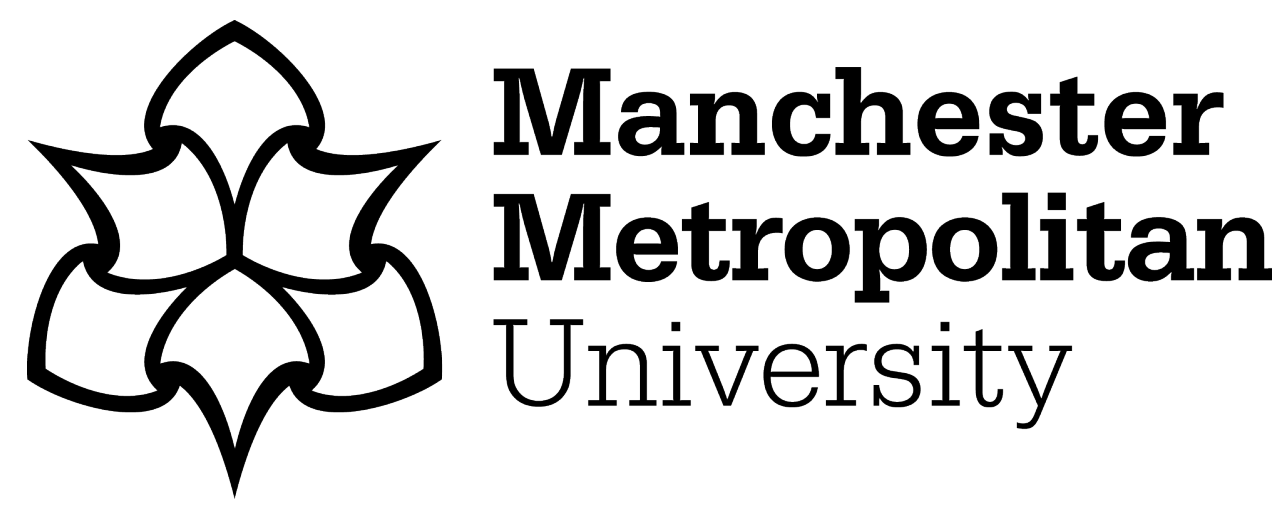

Higgs, Peter, Yarwood, Gemma ORCID logoORCID: https://orcid.org/00000003-1804-7088 and Webb, Lucy ORCID logoORCID: https://orcid.org/00000003-2580-3654 (2020) Highlighting the palliative care needs of people using drugs. Collegian: The Australian Journal of Nursing Practice, Scholarship and Research, 27 (5). pp. 581-582. ISSN 1322-7696

Downloaded from: https://e-space.mmu.ac.uk/625333/

Version: Accepted Version

Publisher: Elsevier

DOI: https://doi.org/10.1016/j.colegn.2020.02.006

Please cite the published version 


\section{Highlighting the palliative care needs of people using drugs}

We welcome the call to action for palliative care reform for underserved populations in a recent editorial of Collegian (Phillips, Bloomer, \& Mills, 2019). The authors note that the integration of a harm reduction philosophy into palliative care services is not always clear and we believe that much more can be done to facilitate this.

Whilst they acknowledge "substance misuse" (sic) as a multi-morbidity we argue that people who inject drugs are an underserved population who need to be specifically identified in these reforms. Evidence tells us that in the area of health care people using illicit drugs are more stigmatised than any other population group (Chan Carusone et al., 2019) and those who are using opiates state that they get inadequate pain relief for fear that they are 'drug seeking' (McNeil, Kerr, Pauly, Wood, \& Small, 2016). Stigma is so entrenched that a great deal more than having a patient-centred philosophy of care is required (Biancarelli et al., 2019). This is also supported by evidence that shows clinicians fear both under- and over-prescribing pain medication to people using opiates (Witham, Yarwood, Wright, \& Galvani, 2019). By explicitly focusing attention on the needs of people who use illicit drugs we can do more to ensure they are considered an important part of this reform agenda.

Recent work in the area (Galvani, 2019) outline a number of issues which need to be considered if we are to be in a position to offer best practice advanced care planning for people who use drugs. These include training and education of both substance use professionals and those working in palliative and end of life care. As noted above, multiple levels of overt and covert stigma occur at both professional and personal levels. Increasing skills and awareness in this area will be paramount to effective support.

The 'nothing about us without us' movement tries to engender a human rights and public health centred approach to HIV and hepatitis C (Jürgens, 2008). The experience from this will help the palliative care sector enormously as this new demographic enters their care. It is an example of where the meaningful involvement of the people who are most affected has resulted in some important policy changes (Madden \& Cavalieri, 2007). This also highlights how working to reduce harm can facilitate the development of policies and practises designed to meet people's needs but putting people front and centre will never be enough.

Instead the involvement of people who use illicit drugs in the development of healthy ageing programs will ensure that access to appropriate palliative care is available when they need it. This is 
as crucial as the nurse-led models of care advocated by Phillips and colleagues. Incorporating the people using services as well as those delivering them into the model of care should maximise the chances of improving the quality of palliative and end of life care.

\section{References}

Biancarelli, D. L., Biello, K. B., Childs, E., Drainoni, M., Salhaney, P., Edeza, A., . . Bazzi, A. R. (2019). Strategies used by people who inject drugs to avoid stigma in healthcare settings. Drug and Alcohol Dependence, 198, 80-86. doi:https://doi.org/10.1016/i.drugalcdep.2019.01.037

Chan Carusone, S., Guta, A., Robinson, S., Tan, D. H., Cooper, C., O'Leary, B., . . Strike, C. (2019). "Maybe if I stop the drugs, then maybe they'd care?" - hospital care experiences of people who use drugs. Harm Reduction Journal, 16(1), 16. doi:10.1186/s12954-019-0285-7

Galvani, S. (2019). Offering the best death possible: supporting people using substances at the end of life. Addiction. doi:10.1111/add.14779

Jürgens, R. (2008). "Nothing about us without us" - Greater, meaningful involvement of people who use illegal drugs: a public health, ethical, and human rights imperative. Toronto: Canadian HIV/AIDS Legal Network, Open Society Institute (International Edition).

Madden, A., \& Cavalieri, W. (2007). Hepatitis C prevention and true harm reduction. International Journal of Drug Policy, 18(5), 335-337.

McNeil, R., Kerr, T., Pauly, B., Wood, E., \& Small, W. (2016). Advancing patient-centered care for structurally vulnerable drug-using populations: a qualitative study of the perspectives of people who use drugs regarding the potential integration of harm reduction interventions into hospitals. 111(4), 685-694. doi:10.1111/add.13214

Phillips, J., Bloomer, M., \& Mills, J. (2019). Extending palliative care for underserved populations: Time to act. Collegian. doi:10.1016/j.colegn.2019.09.009

Witham, G., Yarwood, G., Wright, S., \& Galvani, S. (2019). An ethical exploration of the narratives surrounding substance use and pain management at the end of life: a discussion paper. Nursing Ethics, 969733019871685. doi:10.1177/0969733019871685 